\title{
Efficacy of palliative radiotherapy for gastric bleeding in patients with unresectable advanced gastric cancer: a retrospective cohort study
}

Chihiro Kondoh ${ }^{1,3^{*}}$, Kohei Shitara ${ }^{1,4}$, Motoo Nomura ${ }^{1}$, Daisuke Takahari ${ }^{1}$, Takashi Ura ${ }^{1}$, Hiroyuki Tachibana ${ }^{2}$, Natsuo Tomita ${ }^{2}$, Takeshi Kodaira ${ }^{2}$ and Kei Muro ${ }^{1}$

\begin{abstract}
Background: Bleeding negatively impacts quality of life in patients with unresectable advanced gastric cancer and has the potential to be lethal. When blood transfusion and endoscopic hemostasis are unsuccessful to stop bleeding, radiation to stomach is selected in patients with unsuitable condition for surgery. We performed a retrospective cohort study to clarify the utility of radiotherapy in treating gastric bleeding, particularly for patients with limited life expectancy.
\end{abstract}

Methods: We evaluated the efficacy and safety of palliative radiotherapy in patients with advanced gastric cancer between January 2007 and December 2012 in Aichi Cancer Center Hospital. All patients had gastric bleeding requiring blood transfusion. We defined hemostasis as an increase in hemoglobin level to more than $7.0 \mathrm{~g} / \mathrm{dL}$ together with the cessation of melena or hematemesis for at least 1 week.

Results: During the study period, 313 advanced gastric cancer patients treated in our institution. Of these 17 patients received gastric radiotherapy to stop bleeding. Two patients were excluded from analysis due to combined treatment of intravascular embolization. Eleven out of 15 patients (73\%) had undergone two or more previous chemotherapy regimens. Ten patients (67\%) had an Eastern Cooperative Oncology Group performance status of 3 and 14 patients (93\%) were in palliative prognostic index group B or C. The median total planned radiation dose was $30 \mathrm{~Gy}$ in 10 fractions. At a median interval of 2 days after initiation of radiotherapy, 11 patients (73\%) achieved hemostasis; rebleeding was observed in four patients (36\%). The median hemoglobin level before radiotherapy was significantly increased from 6.0 to $9.0 \mathrm{~g} / \mathrm{dL}(p<0.0001)$. The median volume of red blood cell transfusion was significantly decreased from 1120 to $280 \mathrm{~mL}(p=0.007)$. The median rebleeding-free survival interval was 27 days, with a median overall survival of 63 days. The cause of death was bleeding in 1 patient (7\%) and cancer progression without bleeding in 12 patients (80\%). There were no severe adverse events attributable to radiotherapy.

Conclusions: Palliative radiotherapy for gastric bleeding achieves hemostasis within a short time frame. This appears to be a useful treatment option, especially for patients with end-stage, unresectable advanced gastric cancer.

Keywords: Gastric cancer, Palliative care, Radiotherapy, Hemostasis, Bleeding

\footnotetext{
* Correspondence: hirochi1981@gmail.com

'Department of Clinical Oncology, Aichi Cancer Center Hospital, 1-1

Kanoko-den Chikusa-ku, Nagoya City, Aichi, Japan

${ }^{3}$ Department of Medical Oncology, Japanese Red Cross Nagoya Daiichi

Hospital, 3-35 Michishita-Cho, Nakamura-ku, Nagoya City, Aichi, Japan

Full list of author information is available at the end of the article
} 


\section{Background}

Adenocarcinoma of the stomach is a significant malady, with a worldwide incidence of more than 900 000, causing 700000 deaths in 2012 [1]. Patients with early gastric cancer are commonly treated surgically and with advanced locoregional disease are treated with multimodal approach such as surgery followed by chemotherapy or chemoradiotherapy [2-4] or perioperative chemotherapy or chemoradiotherapy [5, 6]. For patients with advanced gastric cancer (AGC), quality of life is negatively impacted when the tumor causes obstruction and symptoms such as pain or bleeding. Hemoglobin level of less than $6.5 \mathrm{~g} / \mathrm{dL}$ is categorized as life-threatning, blood transfusion is the only intervention option for patients who require immediate correction of anemia. According to the guidelines published by the American Association of Blood Banks, transfusion is recommended for hospitalized patients without cardiovascular disease targeting the threshold of hemoglobin level of 7 to $8 \mathrm{~g} / \mathrm{dL}$ and depending on their symptoms. [7] Radiotherapy (RT) is sometimes used to treat severe anemia due to gastric bleeding in patients with AGC who are not able to undergo surgery, endoscopy, or intravascular embolization. The efficacy of RT for bleeding has been evaluated in patients with non-small-cell lung cancer, cervical cancer, and bladder cancer [8-11]. In patients with AGC, between 54 and $80 \%$ are able to achieve hemostasis with RT [12-17]. In patients who complete a dose of 30 Gy or more, $91 \%$ are hemostatic within 1 month [16]. The survival time of patients with AGC who fail standard chemotherapy is reportedly $3.8-4.3$ months [18-20]. In the present study, we attempted to refine these measurements, focusing on the interval to achieve hemostasis after initiating RT and the eventual cause of death in patients with AGC. These parameters may be more important to patients who are seeking palliative rather than curative treatment.

\section{Methods}

\section{Patients}

For this retrospective cohort study, we reviewed the records of patients with unresectable AGC who received palliative RT to control gastric bleeding. All patients were treated at Aichi Cancer Center Hospital between January 2007 and December 2012. The principal inclusion criteria were: histologically proven inoperable adenocarcinoma in the stomach or in the esophagogastric junction, endoscopically confirmed gastric bleeding, and at least one blood transfusion administered to improve anemia before RT.

A total of 313 patients with AGC were treated at our institution during the study period. Of these, 17 patients had received gastric RT for hemostasis. Two patients with hemorrhagic shock were excluded from analysis due to a history of interventional radiology (IVR) procedures administered within 7 days of beginning RT. All patients gave written informed consent for treatment. The review board of Aichi Cancer Center approved this study and deemed informed consent unnecessary due to its retrospective nature.

\section{Radiotherapy}

RT planning was performed using 3-dimensional radiation planning system with 5 or $10-\mathrm{mm}$ slice thickness of computed tomography $(\mathrm{CT})$ images. The clinical target volume (CTV) was defined as primary lesion, with adequate margins, based on the findings of both endoscopic examination and CT images. Regional lymph nodes were not included in the CTV. The planning treatment volume (PTV) is created from CTV adding margin for clinical treatment set-up. All patients were treated using external $10-\mathrm{MV}$ photon beams from a linear accelerator. Typically, a total dose of 30Gy in 10 fractions was delivered to the PTV using the antero-posterior parallel opposed portals.

\section{Evaluation of treatment and statistical analysis}

The Eastern Cooperative Oncology Group performance status (PS) and the Palliative Prognostic Index (PPI) were used to evaluate patients $[21,22]$. PPI is calculated for each case based on palliative performance scale, the amount of oral intake, and the presence of edema, dyspnea at rest, and delirium. Patients are divided into groups according to projected survival time: group A, 4 to 5 months; group B, 3 months; and group C, less than 3 weeks [22].

Patients' records were reviewed from the time point 30 days before initiating RT until their death. The day of hemostasis was defined without endoscopic evidence as the first day after starting RT that satisfied all of the following criteria for at least 7 consecutive days: an increase in hemoglobin to greater than $7.0 \mathrm{~g} / \mathrm{dL}$, no evidence of melena or hematemesis, and no indication for blood transfusion. Patients who required other hemostatic procedures such as IVR techniques or endoscopic procedures were categorized as failing RT. Patients given blood transfusions after achieving hemostasis were categorized as rebleeding.

Hematologic studies were conducted at least once weekly. The change in hemoglobin level was determined by evaluating the lowest point in the 30 days before starting irradiation and the level 30 days after starting RT; t-testing was used to compare these values. Toxicity was evaluated within 30 days of initiating RT using the National Cancer Institute Common Toxicity Criteria, version 4.0.

Biologically effective dose (BED) is an approximate quantity to compare the different fractionation regimens. Using alpha/beta ratio of 10 for adenocarcinomas, BED was calculated for each cases. 
Rebleeding-free survival (RFS) was measured from the first day of RT until either rebleeding occurred or death from any cause took place. Rebleeding was set at day 1 of RT for patients who never achieved hemostasis. Overall survival (OS) was measured from the first day of RT until death occurred. The median RFS and OS were determined using the Kaplan-Meier method. Statistical analysis was performed using JMP software, version 10.0.2 (Statistical Analysis Software, Inc., Cary, NC). Statistical significance was set at 0.05 (using 2-tailed testing).

\section{Results}

\section{Patient characteristics}

Patient characteristics are listed in Table 1. The median follow-up time was 35.4 months (range, 0.9-82.0 months). The median patient age was 61 years. Male patients predominated, and $67 \%$ of all patients had a poor PS. A total of eight patients (53\%) were in PPI group B, and six patients $(40 \%)$ were in group C. The dominant histology was poorly differentiated adenocarcinoma in seven patients (47\%), and the tumor was located in the gastric body in 11 patients (73\%). All patients had metastatic disease, and 10 (67\%) had organ metastases. Eleven patients (73\%) had received two or more chemotherapy regimens prior to beginning RT (median, 3 regimens).

Concurrent chemotherapy was administered in five patients (33\%). The regimens were as follows: weekly paclitaxel, weekly paclitaxel and trasutuzumab, methotrexate and 5-fluorouracil (5-FU), low-dose cisplatin and 5-FU, and FOLFOX (oxaliplatin, folinic acid and 5-FU). Compared with the concurrent chemoRT group, the RT alone group was older in median age. PPI group $\mathrm{C}$ and peritoneal metastasis were less in RT alone group. The other background factors were balanced between the two groups. Chemotherapy regimens after completion of RT were as follows: weekly paclitaxel in two patients, methotrexate and 5-FU in one patient, trastuzumab and lapatinib in one patient, and docetaxel in one patient. Subsequent chemotherapy was administrated to two patients (20\%) in RT alone group and to three patients $(60 \%)$ in chemoRT group.

\section{Treatment results}

Twelve patients $(80 \%)$ received the dose-fraction regimen of 30 Gy in 10 fractions corresponding to BED $39 \mathrm{~Gy}_{10}$. The others were planned as 40Gy in 20 fractions, 36Gy in 18 fractions, and 30Gy in 12 fractions for one patient respectively; these doses were completed in all but a single patient (93\%) (Table 1). One patient with brain metastases discontinued RT after achieving hemostasis because of restlessness during irradiation. All patients were treated with supportive medications such as proton pump inhibitors, tranexam acid and local thrombin.
Table 1 Patient characteristics

\begin{tabular}{llll}
\hline Characteristics & Radiotherapy & Chemoradiotherapy $^{\text {b }}$ & Total \\
& $(n=10)$ & $(n=5)$ & $(n=15)$ \\
& $\%(n)$ & $\%(n)$ & $\%(n)$
\end{tabular}

\begin{tabular}{lccc}
\hline $\begin{array}{l}\text { Age (years) } \\
\text { Median (range) }\end{array}$ & $62(57-87)$ & $53(42-71)$ & $61(42-87)$ \\
$\begin{array}{lll}\text { Sex } \\
\text { Male }\end{array}$ & $70(7)$ & $80(4)$ & $73(11)$ \\
ECOG performance status & & \\
1 & 0 & $20(1)$ & $1(7)$ \\
2 & $30(3)$ & $20(1)$ & $4(26)$ \\
3 & $70(7)$ & $60(3)$ & $10(67)$
\end{tabular}

Palliative prognostic index group [22]

$\begin{array}{llll}\text { A } & 0 & 20(1) & 7(1) \\ \text { B } & 70(7) & 20(1) & 53(8) \\ \text { C } & 30(3) & 60(3) & 40(6)\end{array}$

Histological type

Well differentiated $10(1) \quad 20(1)$

$\begin{array}{lll}\text { Moderately } & 50(5) & 20(1)\end{array}$

differentiated

$\begin{array}{llll}\text { Poorly } & 40(4) & 60(3) & 47(7)\end{array}$

differentiated

Location

Esophagogastric $20(2) \quad 40(2) \quad 27(4)$
junction

$\begin{array}{llll}\text { Gastric corpus } & 80(8) & 60(3) & 73(11)\end{array}$

Metastatic site ${ }^{a}$

$\begin{array}{llll}\text { Lymph nodes } & 60(6) & 80(4) & 67(10)\end{array}$

$\begin{array}{llll}\text { Liver } & 60(6) & 60(3) & 60(9)\end{array}$

$\begin{array}{llll}\text { Peritoneum } & 30(3) & 60(3) & 40(6)\end{array}$

Prior chemotherapeutic regimen

$\begin{array}{llll}0 & 10(1) & 0 & 7(1) \\ 1 & 20(2) & 20(1) & 20(3) \\ 2 & 10(1) & 20(1) & 13(2) \\ 3 \text { or more } & 60(6) & 60(3) & 60(9) \\ \begin{array}{l}\text { Subsequent chemotherapy } \\ \text { Yes }\end{array} & & \\ \text { Radiotherapy dose (Gy) } & & & \\ 30 & 80(8) & 80(4) & \\ >30 & 10(1) & 20(1) & 13(12) \\ <30 & 10(1) & 0 & 7(1)\end{array}$

Biologically effective dose $\left(\mathrm{Gy}_{10}\right)$

Median (range) $\quad 39(23.4-43.2) \quad 39(39-48) \quad 39(23-48)$

ECOG Eastern Cooperative Oncology Group

${ }^{\mathrm{a}}$ Overlapped data

${ }^{b}$ Paclitaxel in 1; paclitaxel and trastuzumab in 1; methotrexate +5 -fluorouracil (5-FU) in 1; oxaliplatin + folinic acid + 5-FU in 1; low dose cisplatin + 5-FU in 1

${ }^{C}$ Paclitaxel in 2; methotrexate + 5-FU in 1; docetaxel in 1; trastuzumab + lapatinib in 1 
Eleven patients (73 \%) achieved hemostasis. The median time to hemostasis was 2 days (range, 1-9 days). The median hemostatic radiation dose was 6 Gy (range, 3-21 Gy). In the four patients categorized as no hemostasis, no one started RT with thrombocytopenia. Three patients received RT alone and one patient received chemoRT. One patient was rescued by arterial embolization technique and stopped bleeding. None was performed endoscopic procedures. The median hemoglobin level before RT was $6.0 \mathrm{~g} / \mathrm{dL}$; after 30 days, the median was $9.0 \mathrm{~g} / \mathrm{dL}$, a significant increase $(p<0.001)$. The median platelet count was $291,000 / \mathrm{mm}^{3}$ (range, 6.0-53.3) on the day of starting RT. The median red blood cell transfusion volume per month significantly decreased, from $1120 \mathrm{~mL}$ pre-RT to $280 \mathrm{~mL}$ after starting RT $(p=0.007)$ (Fig. 1). In the 11 patients who achieved hemostasis, 4 experienced rebleeding (36\%). At the time of rebleeding, the platelet count less than $50,000 / \mathrm{mm}^{3}$ was observed in one patient with disseminated intravascular coagulopathy due to bone marrow metastasis. The median RFS was 27 days (95\% confidential interval [CI], 1-94 days) (Fig. 2).

The cause of death was gastric bleeding in one patient (7\%) and cancer progression in 12 patients (80\%). Two patients $(13 \%)$ were still alive at the end of the study period. The median OS was 63 days (95\% CI, 20-141 days) (Fig. 2).

In the five patients of chemoRT goup, four patients stopped bleeding. Of them, two patients showed rebleeding 27 and 147 days later respectively. The median OS was 63 days (95\%CI, 39-259 days).

\section{Toxicity}

Grade 1 nausea and pleural effusion were documented in two patients. Fatigue, vomiting, and diarrhea were noted in one patient each. One patient required treatment for grade 2 hypertension after achieving hemostasis. As a result of concurrent or subsequent chemotherapy, Grade 3/4 neutropenia was documented in 3 patients. Grade 4 thrombocytopenia and creatinine elevation developed in one patient each, findings we attributed to disease progression (Table 2).

\section{Discussion}

Gastric cancer is not adequately sensitive to RT alone; thus, multimodal therapeutic approaches with surgery and chemotherapy have been developed [2-6, 23]. Henning et al. showed an advantage in locoregional control in patients undergoing chemoradiation who received a dose of greater than $54 \mathrm{~Gy}$, but no OS benefit was seen [24]. However, from the palliative point of view, Asakura et al. reported that a radiation dose of $30 \mathrm{~Gy}$ in ten fractures is adequate to control bleeding from gastric cancer [15]. The hemostatic rate observed in the present study is almost the same as Asakura et al's and supports their results.

The mechanism of hemostasis induced by irradiation is not clearly identified. The irradiation procedure is widely thought to aggregate platelets or to damage the vascular endothelial cells. Radiation has also been shown to induce embolism of vessels, both in vitro and in vivo [25-27]. In the preclinical experimental models of rats and mice, platelet aggregation is observed $3 \mathrm{~min}$ after irradiation [28], with tissue factor (the primary initiator of blood coagulation, expressed on peripheral mononuclear cells) appearing after 1 day. Procoagulant activity is seen for duration of 7 days [29]. These mechanisms may support the early hemostatic response to RT observed in our patients.

OS and RFS are strongly associated with individual patient characteristics. Previous reports of palliative RT
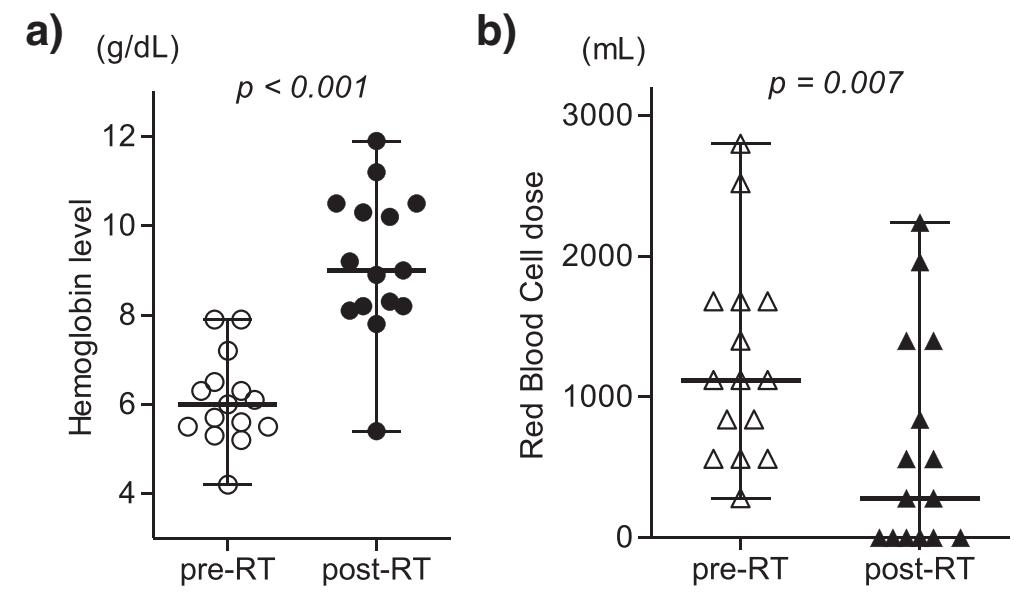

Fig. 1 a Comparison of hemoglobin levels prior to and 30 days after initiation of gastric radiation therapy (RT). The horizontal bars represent the mean (long bar) and the range (short bars). b Comparison of the amount of transfused red blood cells 30 days before and 30 days after starting gastric RT. The horizontal bars represent the mean (long bar) and the range (short bars) 


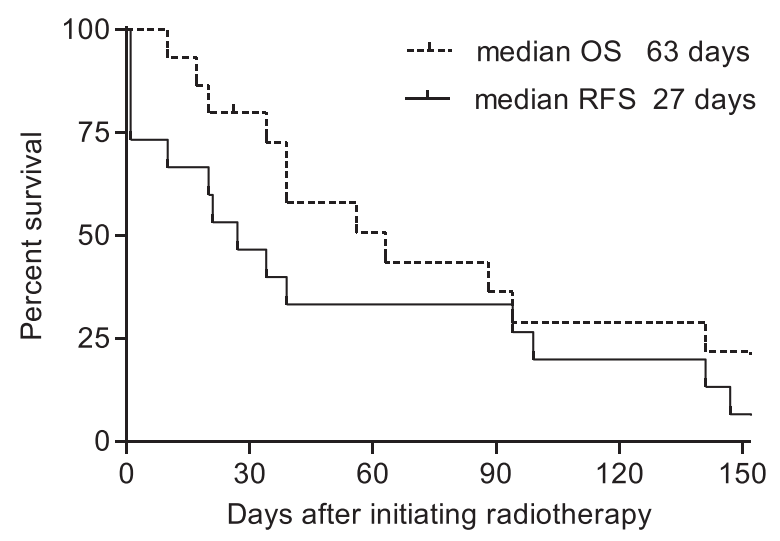

Fig. 2 Rebleeding-free survival (RFS) and overall survival (OS) after gastric radiation therapy

performed for gastric bleeding had study populations of 30-40 \% chemo-naïve patients; $60-80 \%$ had a good PS (PS1/2). Our study population was $7 \%$ chemo- naïve, and $33 \%$ had a good PS; hence, the prognosis of our patients is the poorest reported thus far. Fourteen of our patients (93\%) were categorized as PPI group B or C, a finding that confers a prognosis of less than 3 months survival but also indicates potential benefit from the use of RT. In patients with such a limited life expectancy, it is important to use minimally invasive treatment methods whenever possible. Hypofractionated RT was previously investigated, in a randomized, controlled trial, for the management of patients with bladder cancer who are unsuitable for curative treatment and who have an estimated 3-month survival prognosis [11]. A dose of 21 Gy in 3 fractions, given on alternate weekdays over 1 week, and a dose of 35 Gy in 10 fractions, given over 2 weeks, produced improvement in symptoms in 64 and $71 \%$ of patients, respectively, with no evidence of a difference in efficacy or toxicity between the dosage groups. Hypofractionated RT may induce more late toxicity in patients

Table 2 Treatment toxicity

\begin{tabular}{lllll}
\hline Toxicity & Grade & & & \\
\cline { 2 - 5 } & 1 & 2 & 0 & 4 \\
\hline Nausea & 2 & 0 & 0 & 0 \\
Vomiting & 1 & 0 & 0 & 0 \\
Diarrhea & 1 & 0 & 0 & 0 \\
Fatigue & 1 & 0 & 0 & 0 \\
Pleural effusion & 2 & 0 & 0 & 0 \\
Hypertension & 0 & 1 & 0 & 1 \\
Creatinine increased & 1 & 0 & 0 & 0 \\
Bilirubin increased & 2 & 1 & 1 & 2 \\
Neutropenia & 3 & 0 & 0 & 1 \\
Thrombocytopenia & 2 & 1 & & 0 \\
\hline
\end{tabular}

with other types of cancer [30], so it is recommended only for patients with a limited life expectancy. In the setting of AGC refractory to standard chemotherapy, hypofractionated RT might be an option for patients in PPI group $\mathrm{B}$ or $\mathrm{C}$.

Previous studies have not provided information about the cause of death in their patients. Although our results may be fairly premature, with two patients still living, $80 \%$ of our patients died from disease progression, exhibiting organ failure or physical debilitation, not bleeding from stomach.

One of the major limitations of the present study is the method of patient selection. We excluded two patients from analysis because they had previously undergone intravascular catheter embolization. One of these patients achieved hemostasis with RT alone, but the other patient never stopped bleeding and went on to die of hemorrhage. One of the study patients had continuing hemorrhage after starting RT alone and underwent IVR rescue treatment for a pseudoaneurysm, detected along a branch of the left gastric artery. The condition common to these 3 patients is hemorrhagic shock, which may be an indicator of unsuitability for RT. Other limitations of this study are the small sample size and the retrospective, single-institution study design.

\section{Conclusions}

In conclusion, our results, although limited, suggest that palliative RT may be a useful treatment option to control gastric bleeding in patients with unresectable AGC. Patients who respond to treatment typically achieve hemostasis within 2 days, and the benefits persist for longer than 1 month. These patients may avoid death from hemorrhage. Additional investigation is necessary in order to clarify the ideal RT dose and to select the most appropriate candidates for treatment.

\section{Abbreviations}

AGC: Advanced gastric cancer; RT: Radiotherapy; IVR: Interventional radiology; $\mathrm{CT}$ : Computed tomography; CTV: Clinical target volume; PTV: Planning treatment volume; PS: Performance status; PPI: Palliative prognostic index; BED: Biologically effective dose; RFS: Rebleeding-free survival; OS: Overall survival; 5-FU: 5-fluorouracil; Cl: Confidential interval.

\section{Competing interests}

The authors declare that they have no competing interests.

\section{Authors' contributions}

CK and MN proposed the study. CK was responsible for the overall study coordination including data collection, transcription of the data, statistical analysis and wrote the initial draft of the manuscript. KS reviewed the study concept, and critically revised the manuscript. MN participated in the revision of manuscript. DT revised the manuscript. TU participated in the discussion of the study concept and the revision of the manuscript. HT revised the study concept including cohort selection and transcription of the data, and the draft manuscript. NT revised the manuscript. TK supervised the study and revised the manuscript. KM supervised the study and participated in the revision of initial concept and the manuscript. All authors read and approved the final manuscript. 


\section{Author details}

1Department of Clinical Oncology, Aichi Cancer Center Hospital, 1-1 Kanoko-den Chikusa-ku, Nagoya City, Aichi, Japan. ²Department of Radiation Oncology, Aichi Cancer Center Hospital, 1-1 Kanoko-den Chikusa-ku, Nagoya City, Aichi, Japan. ${ }^{3}$ Department of Medical Oncology, Japanese Red Cross Nagoya Daiichi Hospital, 3-35 Michishita-Cho, Nakamura-ku, Nagoya City, Aichi, Japan. ${ }^{4}$ Department of Gastroenterology and Gastrointestinal Oncology, National Cancer Center Hospital East, 6-5-1 Kashiwanoha, Kashiwa City, Chiba, Japan

Received: 27 December 2014 Accepted: 22 July 2015

Published online: 04 August 2015

\section{References}

1. Ferlay J, Soerjomataram I, Ervik M, Dikshit R, Mathers C, Robelo M, Parkin DM, Forman D, Bray F: GLOBOCAN 2012 v1.0, Cancer Incidence and Mortality Worldwide: IARC Cancer Base No. 11. Lyon, France: International Agency for Research on Cancer. http://globocan.iarc.fr. Accessed 30 November 2014

2. Macdonald JS, Smalley SR, Benedetti J, Hundahl SA, Estes NC, Stemmermann GN, et al. Chemoradiotherapy after surgery compared with surgery alone for adenocarcinoma of the stomach or gastroesophageal junction. N Engl J Med. 2001;345:725-30.

3. Sakuramoto S, Sasako M, Yamaguchi T, Kinoshita T, Fujii M, Nashimoto A, et al. Adjuvant chemotherapy for gastric cancer with S-1, an oral fluoropyrimidine. N Engl J Med. 2007:358:1810-20.

4. Bang YJ, Kim YW, Yang HK, Chung HC, Park YK, Lee KH, et al. Adjuvant capecitabine and oxaliplatin for gastric cancer after D2 gastrectomy (CLASSIC): a phase 3 open-label, randomised controlled trial. Lancet. 2012;379:315-21.

5. Cunningham D, Allum WH, Stenning SP, Thompson JN, Van de Velde CJ, Nicolson M, et al. MAGIC trial participants: perioperative chemotherapy versus surgery alone for resectable gastroesophageal cancer. N Engl J Med. 2006;355:11-20.

6. van Hagen P, Hulshof MC, van Lanschot JJ, Steyerberg EW, van Berge Henegouwen MI, Wijnhoven BP, et al. Preoperative chemoradiotherapy for esophageal or junctional cancer. N Engl J Med. 2012;366:2074-84.

7. Carson JL, Grossman BJ, Kleinman S, Tinmouth AT, Marques MB, Fung MK, et al. Clinical Transfusion Medicine Committee of the AABB: Clinical Transfusion Medicine Committee of the AABB. Red blood cell transfusion: a clinical practice guideline from the AABB* Ann Intern Med. 2012;157:49-58.

8. No author listed. A Medical Research Council (MRC) randomised trial of palliative radiotherapy with two fractions or a single fraction in patients with inoperable non-small-cell lung cancer (NSCLC) and poor performance status. Medical Research Council Lung Cancer Working Party. Br J Cancer. 1992;65:934-41

9. Langendijk JA, ten Velde GP, Aaronson NK, de Jong JM, Muller MJ, Wouters EF. Quality of life after palliative radiotherapy in non-small cell lung cancer: a prospective study. Int J Radiat Oncol Biol Phys. 2000;47:149-55.

10. van Lonkhuijzen $\mathrm{L}$, Thomas $\mathrm{G}$. Palliative radiotherapy for cervical carcinoma, a systematic review. Radiother Oncol. 2011;98:287-91.

11. Duchesne GM, Bolger JJ, Griffiths GO, Trevor Roberts J, Graham JD, Hoskin PJ, et al. A randomized trial of hypofractionated schedules of palliative radiotherapy in the management of bladder carcinoma: results of medical research council trial BA09. Int J Radiat Oncol Biol Phys. 2000;47:379-88.

12. Tey J, Back MF, Shakespeare TP, Mukherjee RK, Lu JJ, Lee KM, et al. The role of palliative radiation therapy in symptomatic locally advanced gastric cancer. Int J Radiat Oncol Biol Phys. 2007;67:385-8.

13. Kim MM, Rana V, Janjan NA, Das P, Phan AT, Delclos ME, et al. Clinical benefit of palliative radiation therapy in advanced gastric cancer. Acta Oncol. 2008:47:421-7.

14. Hashimoto K, Mayahara H, Takashima A, Nakajima TE, Kato K, Hamaguchi T, et al. Palliative radiation therapy for hemorrhage of unresectable gastric cancer: a single institute experience. J Cancer Res Clin Oncol. 2009;135:1117-23.

15. Asakura H, Hashimoto T, Harada H, Mizumoto M, Furutani K, Hasuike N, et al. Palliative radiotherapy for bleeding from advanced gastric cancer: is a schedule of $30 \mathrm{~Gy}$ in 10 fractions adequate? J Cancer Res Clin Oncol. 2011;137:125-30.

16. Lee JA, Lim do H, Park W, Ahn YC, Huh SJ. Radiation therapy for gastric cancer bleeding. Tumori. 2009;95:726-30.
17. Tey J, Choo BA, Leong CN, Loy EY, Wong LC, Lim K, et al. Clinical outcome of palliative radiotherapy for locally advanced symptomatic gastric cancer in the modern era. Medicine (Baltimore). 2014;93:e118.

18. Fuchs CS, Tomasek J, Yong CJ, Dumitru F, Passalacqua R, Goswami C, et al. Ramucirumab monotherapy for previously treated advanced gastric or gastro-oesophageal junction adenocarcinoma (REGARD): an international, randomised, multicentre, placebo-controlled, phase 3 trial. Lancet. 2014;383:31-9.

19. Ohtsu A, Ajani JA, Bai YX, Bang YJ, Chung HC, Pan HM, et al. Everolimus for previously treated advanced gastric cancer: results of the randomized, double-blind, phase III GRANITE-1 study. J Clin Oncol. 2013:31:3935-43.

20. Kang JH, Lee SI, Lim do H, Park KW, Oh SY, Kwon HC, et al. Salvage chemotherapy for pretreated gastric cancer: a randomized phase III trial comparing chemotherapy plus best supportive care with best supportive care alone. J Clin Oncol. 2012;30:1513-8.

21. Buccheri G, Ferrigno D, Tamburini M. Karnofsky and ECOG performance status scoring in lung cancer: a prospective, longitudinal study of 536 patients from a single institution. Eur J Cancer. 1996:32A:1135-41.

22. Morita T, Tsunoda J, Inoue S, Chihara S. The Palliative Prognostic Index: a scoring system for survival prediction of terminally ill cancer patients. Support Care Cancer. 1999;7:128-33.

23. Buergy D, Lohr F, Baack T, Siebenlist K, Haneder S, Michaely H, et al. Radiotherapy for tumors of the stomach and gastroesophageal junction - a review of its role in multimodal therapy. Radiat Oncol. 2012;7:192.

24. Henning GT, Schild SE, Stafford SL, Donohue JH, Burch PA, Haddock MG et al. Results of irradiation or chemoirradiation for primary unresectable, locally recurrent, or grossly incomplete resection of gastric adenocarcinoma. Int J Radiat Oncol Biol Phys. 2000;46:109-18.

25. Rosenberg RD, Aird WC. Vascular-bed-specific hemostasis and hypercoagulable states. N Engl J Med. 1999;340:1555-64.

26. Borissoff Jl, Spronk HMH, ten Cate $\mathrm{H}$. The hemostatic system as a modulator of atherosclerosis. N Engl J Med. 2011;364:1746-60.

27. Jourdan A, Aguejouf O, Imbault P, Doutremepuich F, Inamo J, Doutremepuich C. Experimental thrombosis model induced by free radicals. Application to aspirin and other different substances. Thromb Res. 1995;79:109-23.

28. Born GV. Aggregation of blood platelets by adenosine diphosphate and its reversal. Nature. 1962;194:927-9.

29. Goldin-Lang P, Niebergall F, Antoniak S, Szotowski B, Rosenthal P, Pels K, et al. lonizing radiation induces upregulation of cellular procoagulability and tissue factor expression in human peripheral blood mononuclear cells. Thromb Res. 2007;120:857-64.

30. Onsrud M, Hagen B, Strickert T. 10-Gy single-fraction pelvic irradiation for palliation and life prolongation in patients with cancer of the cervix and corpus uteri. Gynecol Oncol. 2001;82:167-71.

\section{Submit your next manuscript to BioMed Central and take full advantage of:}

- Convenient online submission

- Thorough peer review

- No space constraints or color figure charges

- Immediate publication on acceptance

- Inclusion in PubMed, CAS, Scopus and Google Scholar

- Research which is freely available for redistribution 